\title{
Jigsaw On Line Model as the Improvization of Learning Methods in the Covid-19 Pandemic
}

\author{
Istiqomah $^{1}$, Bambang Budi Wiyono², Hetty Rahmawati ${ }^{3}$, Endang Prastuti ${ }^{4}$, Nur Eva ${ }^{5}$, \\ Tristiadi Ardi Ardani6 \\ ${ }^{1}$ Psychology Faculty, University of Muhammadiyah Malang, \\ ${ }^{2}$ Education Faculty, State University of Malang, \\ 1,3,4,5 Psychology Education Faculty, State University of Malang, \\ ${ }^{6}$ Faculty of Psychology of the State Islamic University ( UIN ) Maulana Malik Ibrahim Malang, Indonesia \\ istiqomah@umm.ac.id ${ }^{1}$, bambang.budi.fip@um.ac.id², hetti.rahmawati.fppsi@um.ac.id ${ }^{3}$, \\ nur.eva.fppsi@um.ac.id ${ }^{4}$, endang.prastuti.fpsi@um.ac.id ${ }^{5}$, tristiadiardiardani@psi.uin-malang.ac.id ${ }^{6}$
}

\begin{abstract}
Jigsaw cooperative learning is a learning model that encourages active students and helps each other in mastering the subject matter by dividing it into groups of origin and groups of experts in teaching and learning activities. Each group of experts is responsible for a material or subject. After the expert group has finished studying one topic of their expertise, each student returns to their home group to teach their expertise material to their friends in a discussion group. The aim of the study was to test whether the online Jigsaw method was effective for college students. The jigsaw method is done online, so it's done using zoom software, and goegle meet. The research subjects were 98 students in the 5th semester. The data analysis technique used the Independent sample T-test inferential statistics. The result of the analysis shows that there are significant differences between students who get online learning using the jigsaw method and the conventional method.
\end{abstract}

Keywords

Cooperative learning, jigsaw model, on line method

Article Received: 10 August 2020, Revised: 25 October 2020, Accepted: 18 November 2020

\section{Introduction}

The spread of Covid-19 requires us to be at home and maintain our distance (social distancing). Government policy in the field of education related to social distancing in order to break the chain of the spread of the corona virus is to close schools at all levels. Schools are closed but that does not mean holidays without a learning process, but instead the learning system is transferred to online or online learning. Government policies with an online learning system make educators able to apply their technological capabilities. The government's hope is that students' academic performance can still run well. In this condition, it is hoped that the learning process will continue to run well and students will not feel bored with the methods given by the teacher.

Some subjects require a deeper understanding, especially in subjects that require cognitive abilities, for example mathematics, statistics and construction of measuring instruments. The measuring instrument construction course is a subject that is considered difficult because it combines the construction of measuring instruments and statistics. This subject when taught face-to-face is considered a difficult subject and will be even more difficult if taught online. Research (Nurvita et al, 2020) on the metacognition analysis of student difficulties, namely students cannot understand what it is according to their difficulties, students also cannot use the information obtained in the concepts they think of, students cannot choose the steps that must be done to solve problems the student cannot solve the problem correctly. In mathematical analysis, students have difficulty connecting the information in the problem with the previous material. The results of the study show that students will find it easier to understand these difficulties by using the jigsaw method. The results of research by Johnson, Johnson, \& Stanne (2000) show that learning methods have a positive effect on student achievement. Cooperative learning methods compared to competitive learning show significant differences in results 
and the diversity of cooperative learning methods has a strong impact on learning effectiveness.

Students need improvisation in learning measuring instrument construction in which this course combines the concept of compiling measuring instruments and statistics. With this improvisation, the hope is that he can change his perception of measuring instrument construction from a difficult subject to a fun course. Supported by research by Evans (2007) which states that students' positive attitudes towards statistics courses correlate with learning achievement.

How to teach is an effective way to improve student academic performance and change students' perceptions of learning statistics into lessons that are not difficult and fun (Fitzmaurice, Leavy, \& Hannigan, 2013). One of the learning strategies used is cooperative learning or what is commonly referred to as cooperative learning. Cooperative Learning is a learning strategy that focuses on grouping students with different academic ability levels into small groups of students working together to achieve shared learning goals (Johnson \& Johnson, 1999: Johnson, Johnson, \& Stanne, 2000). Students are taught special skills in order to work well together in their groups, such as explaining to their group of friends, respecting friends' opinions, discussing regularly, students who are good at helping the weaker, and so on. Cooperative learning as a form of learning method, which requires students to work collaboratively in small, heterogeneous groups by helping each other to learn the assigned task (Strother, 1990: Azmin, 2015). Cooperative learning is further defined as a type of studentcentered teaching in which a heterogeneous group of students work together to achieve a common goal (Kagan, 1994: Azmin, 2015).

The reason for using learning strategies using cooperative learning is because it will provide students with an understanding of the importance of group collaboration but still pay attention to individual efforts. Therefore it is necessary in learning to provide an understanding of the importance of collaboration in groups. Studentcentered cooperative learning with instructional strategies is facilitated by the instructor in small groups of students who are responsible for their own learning and the learning of all group members. This learning strategy the teachers will organize students into small groups that work together and help each other learn academic content and achieve the same goals. Teachers organize and control the learning environment, design learning activities and social interactions, and structure teamwork. In this strategy each student participates in a team and there is cooperation between team members and collective efforts that facilitate understanding of the subject matter (Gloria Ibemenji, Sunday, \& Chijioke, 2019).

Slavin (1995) cooperative learning has benefits, among others: (1) increasing the totality of time on assignments; (2) increase self-esteem; (3) improve attitudes towards subjects, teachers and schools; (4) improve attendance; (5) mutual understanding of individual differences; (6) reduce interpersonal conflicts; (7) reduce apathy; (8) deepen understanding; (9) increase motivation; (10) improve learning outcomes; and (11) enlarge retention. In addition, Woolfolk (2010) states that cooperative learning improves the ability to see the world from the point of view of others, better relationships between different ethnic groups at school or in the classroom, self-confidence, greater acceptance of disabled and low-ability students. . Interaction with peers that students really like is part of the learning process. The need to be accepted in the group tends to be fulfilled.

The cooperative learning model (Johnson et al., 2000) consists of: (1) Student Team Achievement Division (STAD), (2) Jigsaw (3) Team Game Tournament (TGT) is a type of cooperative learning that places students in study groups with the tournament play. (4) Group investigation (GI). (5) Rotating Trio Exchange, (6) Group Resume (7) Team Assisted Individualy (TAI) combines cooperative learning with individual teaching. (8) Cooperative Integrated Reading and Composition. Jigsaw is a cooperative learning strategy where the learning system is divided into several pieces of information and then given to groups of students who want to then explain to each other their parts and produce all picture puzzles that must be solved (Aronson \& Patnoe, 1997). The Jigsaw learning procedure is a highly structured cooperative learning method originally created by Aronson (Aronson, 2005; Aronson \& Patnoe, 
1997; Heden, 2003). In applying the Jigsaw Method, the teacher introduces the topic and its subtopics. The students were then divided into groups, where they were each assigned a different subtopic within the group. The next step requires students to leave their core group to form 'expert' groups where these students focus on one subtopic, research and discuss it. Therefore, students become experts on the subtopics that have been assigned to them. Finally, all group members will learn from each expert group discussion and will benefit from each other.

The results of Walker \& Crogan's (1998) research on the jigsaw method associated with academic performance, self-esteem and peer relationships show that the jigsaw method can improve student academic performance. The relationship between groups will increase individual achievement. According to Khine et al. (2019) The jigsaw type learning model is a cooperative learning model where students learn in small groups consisting of 4-6 students heterogeneously. In this jigsaw learning there are groups of origin and groups of experts. The home group is the parent group of students whose members are students with various abilities and backgrounds. Expert group is a group of students consisting of members of different origin groups and assigned to study and explore certain topics and deliver tasks related to the topic to be explained to the home group.

The Jigsaw method is an interdependence-based learning method because group members have one unit of information (value resource) needed so that the group can complete tasks successfully, but in the usual application of jigsaw student performance is tested and rewarded individually so that usually there is no interdependent fate (Walker \& Crogan, 1998). Jigsaw is considered a fun learning model where class members will be active in the learning process. This activity usually works best if students can meet face to face or they can work with friends directly.

The Jigsaw learning method is not only implemented face-to-face but can be implemented online. So to make students feel happy and comfortable in receiving the subject matter, the teacher uses cooperative learning online. Applications that can be used are google meeting, mocrosoft team, gooegle classroom, zoom LMS etc. Each has strengths and weaknesses, but by using this application we can collect approximately 50-100 students, so it is as if we will discuss directly in class. With the provisions of the questions, we have submitted them to each group first.

The online learning system with the jigwsaw method is a new breakthrough in utilizing technology to improve student academic performance in various conditions. The online Jigsaw method is an alternative that can be used to overcome student boredom in carrying out the online learning process during the Covid pandemic. Supported by research conducted by Kordaki (2014), this study presents an innovative implementation of the Jigsaw collaboration method in the context of an e-learning system based on open source learning designs such as LAMS, with special reference to learning important issues in Computer Science. These problems include: (a) various computer technologies used in everyday life and the consequences of their utilization, (b) various computer systems serving different tasks, (c) the dynamic evolution of information technology in our time. The innovative implementation of the Jigsaw method in LAMS is based on the fact that (a) the task assigned to the expert group consists of various investigative activities in the real world - where computers are used - and not just studying various learning materials as is usually proposed (b) for the whole design. collaborative activity, an intuitive 'design learning' based online tool provided by LAMS.

The advantages of the jigsaw cooperative learning model are: (a) providing opportunities for students to find their own concepts and ways of solving problems, (b) giving students the opportunity to create creativity in communicating with their group of friends, (c) accustom students to being open however firmly, (d) increase student motivation, (e) assist teachers in achieving learner goals. Because cooperative learning steps are easy to implement in schools, (f) encourage teacher motivation to create teaching media, because media is so important in cooperative learning. 
Whereas the weakness of the jigsaw type cooperative learning model is that it takes a long time to carry out discussions, such as regular group learning, students who are good at mastering the course of the discussion, so students who are less intelligent have less opportunity to express their opinions, because they are not used to learning to express opinions and have to get help from other friends who are more powerful. In addition, in the application of the cooperative learning model, groups that feel strange and difficult to work together will find it difficult. In order for cooperative learning to be carried out well, students must be given an activity sheet (LK), which can contain questions or assignments that are planned to be taught. During group work, the task of group members is to achieve the completeness of the material presented by the teacher and to help each other's groupmates to achieve material completeness.

Slavin (2009) in his research stated that cooperative learning is superior in helping students understand difficult concepts. Proponents of Cooperative Learning believe that cooperative reward structures can improve student performance on academic assignments.

Based on the above explanation, the purpose of this study is to determine the effectiveness of online learning with the jigsaw method with online learning using conventional methods. The benefit of this research is that the online learning method using the jigsaw method is expected to improve student learning achievement, reduce student boredom in learning and as an improvisation of teacher learning models in the teaching and learning process.

\section{Method}

This research is an experimental study with a Posttest-Only Control Design research design. In this design, there are two groups chosen randomly.

The first group is the experimental class (X1) and the second group is the control class (X2). In the experimental class (X1) given treatment using the online learning system Jigsaw cooperative learning model, while the control class (X2) conventional online learning class.

\section{Research subject}

The subjects of this research were 98 students in the 5th semester. The research subjects were divided into 2 groups. Group A as many as 49 students were taught using a conventional online system and group B, totaling 49 students, were taught using the online method with the Jigsaw learning model.

\section{Research procedure}

\section{Preparation from the teacher}

Lecturers prepare learning materials in one semester with courses carried out online using the jigsaw method and online classes with conventional methods. Online classes with the jigsaw learning model will be divided into groups of students from various levels of ability. Whereas online classes are conventionally the learning process using only the lecture model without being divided into various groups and students will try themselves to understand the material obtained, this model is usually called the competitive learning model. Learning the jigsaw model begins with learning a chapter or subject, so that each group member holds material on a different topic. Each student from each group holding the same material then gathers in a new group called the expert group. Each expert group is responsible for a chapter or subject. After the expert group has finished studying one topic of their expertise, each student returns to their home group to teach their expertise material to their friends in one group in the form of a discussion.

\section{Group}

Groups are divided based on classes that impose online lectures using the jigsaw method called class A and classes that do online but don't use the jigsaw method are called class B. Classes that carry out online learning online with the jigsaw method as an experimental group (class A) and students who do online learning but do not do 
online learning using the jigsaw method as a control group (class B).

\section{Preparation from students}

Students who are the research samples are 5th semester students who are currently taking measuring instrument construction courses. Students in online jigsaw classes use the LMS application, goegle meet and zoom. Meanwhile, conventional class students only use goegle meet.

\section{Time}

The experiment was conducted in 2 weeks after the study contract at the beginning of the meeting. The experiment was carried out for 13 weeks.
In this experiment the measurement was carried out by looking at the results of the practical scores of students who did the jigsaw model online learning and those who did not use the jigsaw learning model. Data analysis used Independent sample t-test analysis with the help of JASP software (Version 0.13.1). Independent sample ttest was used to test the mean difference between two independent sample groups (Goss-Sampson, 2018).

\section{Result and Disscussion}

The results showed that the average class A was higher than class B where class A used online learning with the jigsaw method and class B was a class with online learning but used conventional online learning methods. The complete table is as follows:

\section{Measurement}

Table 1. Data Deskriptio

\begin{tabular}{llllll}
\hline \multicolumn{6}{c}{ Group Descriptives } \\
\hline \multirow{2}{*}{ Result } & Group & N & Mean & SD & SE \\
& Class A & 49 & 85.55 & 5.25 & 0.75 \\
& Class B & 49 & 77.04 & 7.44 & 1.06 \\
\hline
\end{tabular}

The results showed that there was a significant difference between classes that carried out online learning using the jigsaw method and online classes that used traditional methods. Evidenced by a value of $t=6.54$ with a significance $<0.001$, the full results can be seen in the following table:

Table 2. Independent $t$ test

\begin{tabular}{|c|c|c|c|}
\hline \multicolumn{4}{|c|}{ Independent Samples T-Test } \\
\hline & $\mathbf{t}$ & df & $\mathbf{p}$ \\
\hline Result & 6.54 & 96 & $<.001$ \\
\hline
\end{tabular}

Note. Student's t-test.

This analysis has fulfilled the normality and homogeneity test, the normality test using the Shapiro-Wilk class A and B, respectively, shows a significance> 0.05 meaning that the data is normal, the complete data is in the following table:

Table 3 . Test Normalitas Shapiro-Wilk

Test of Normality (Shapiro-Wilk)

\begin{tabular}{lll}
\hline W & p \\
\hline
\end{tabular}




\begin{tabular}{llll}
\hline & & W & p \\
\hline Result & Class A & 0.96 & 0.08 \\
& Class B & 0.97 & 0.24 \\
\hline
\end{tabular}

Note. Significant results suggest a deviation from normality

The results of the homogeneity test showed that the research data was homogeneous, with the result of the test of equality of variances
(Levene's) significance> 0.05 . The full results are in the table below:

Table 4. Test of Homogenitas

Test of Equality of Variances (Levene's)

\begin{tabular}{cccc}
\hline & F & df & p \\
\hline Result & 2.84 & 1 & 0.10 \\
\hline
\end{tabular}

By using the jigsaw method students will find it easier to understand the material because there are more varied students who have more ability to teach students who do not understand in their groups. The jigsaw method makes students or group members responsible for the success of the group and requires students to be more creative and think fast. The online jigsaw method is very effective in various conditions, especially during the Covid-19 pandemic because it can improve students' ability to learn to process information and improve communication skills and student academic achievement. Supported by research conducted by Hakim \& Sakti C (2019) which states that the jigsaw type cooperative learning is learning that focuses on discussion by the expert group and the home group. Discussions conducted by students aim to understand the material being studied. The results showed that the application of the Jigsaw cooperative learning model was able to improve learning outcomes in economic subjects.

Subjects are students who apply the Jigsaw system on line in the measuring instrument construction course. The method used is by providing materials and assignments, tasks are carried out online in groups and presented in groups as well. Each member of the group must be responsible for the success of the group task and help each other. The existence of good group work will improve student achievement and academic performance. In line with the results of the study which stated that the increase in student performance in the jigsaw method was due to: (1) students becoming active students in class; and (2) the jigsaw method promotes interdependent learning and has a collaborative structure (Aronson, Bridgeman, and Geffner, 1978: Azmin 201). This is supported by Şahin's (2011) research findings which focus on student achievement in writing courses. However, current Brunei research also measures students' ability to write evaluative essays. Johnson and Johnson (1994) support the effectiveness of the jigsaw method because it allows students to have individual accountability and allows students to actively interact with their peers.

The Jigsaw learning model with an online learning system provides a new discourse, especially in the learning process during the Covid pandemic because it will reduce boredom and provide a lot of improvisation. Research conducted by Weidman \& Bishop (2009) states that the jigsaw model can be used in higher education courses with an online system with interdependence, individual accountability, social skill development, and promotional interactions.

The technique used was a qualitative case study design to examine a 6-week online literature course incorporating three jigsaw activities. Analysis of online questionnaires, transcripts from in-depth interviews, and course documents revealed that jigsaw activities yielded mixed 
results with respect to the key characteristics of cooperative learning using CMC (computer mediating communication). The online jigsaw method is very effective in a variety of conditions. The results showed that the jigsaw method made student group members responsible for the success of the group. This is consistent with one of the 5 principles in cooperative learning (Cooper, Robinson, \& McKinney, 1994; Johnson et al., 1984; Johnson, Johnson, \& Smith, 1998; Slavin, 1991; Weidman \& Bishop, 2009). The principle in cooperative learning is individual responsibility, students learn together, but each individual is required to be accountable for their learning outcomes. This means that one effort from one student will affect the efforts of other students. Every learning objective must be clear and understandable to students and there is confidence that students will be able to do it. If students succeed in achieving goals in groups, students also succeed individually. Jigsaw is designed to increase students' sense of responsibility towards their own learning and those of others. Students not only learn the material given, but also must be ready to give and teach the material to other group members. Thus, students depend on each other and must work together to study the assigned material.

The online jigsaw method improves students' abilities in learning to process information and improves communication skills in accordance with one of the principles of cooperative learning. These principles are communication between members, students 'skills in listening to other students, solving conflicts, supporting and motivating other students, taking initiative, showing happy expressions when other students succeed, and being able to criticize other students' ideas (not criticizing the person). Skills like this need to be demonstrated by students collaboratively. Supported by research conducted by (Karacop, 2017) which states that students have a higher level of achievement in physics subjects taught through the Jigsaw method based on cooperative learning compared to laboratory methods.

The type of jigsaw cooperative learning technique is a learning model that will provide several advantages, namely that it can prevent and reduce conflict problems caused by differences between students, learning becomes better and more interesting, increases student learning motivation, and increases comfort in the process learning. This is in line with the research conducted by (Purba \& Sinaga, 2020) which states that the cooperative learning model is very suitable for students who have low learning motivation.

Jigsaw technique provides many advantages, especially in improving student academic performance. Academic performance is the ability of student achievement, student academic skills and the level of product completion as well as the accuracy of the products produced based on the curriculum. Research conducted by Azmin (2015) states that students prefer to use the jigsaw learning method than other learning and using the jigsaw method can improve student academic performance. This study supports the use of jigsaw-based cooperative learning. Supported by research conducted by Miaz (2015) in his research states that the learning procedure with the jigsaw helps students to perform better. Students benefit from techniques by developing social skills. This study aims to determine the social studies achievement of fifth grade students of Bukittinggi State Elementary School, West Sumatra. This research is based on the problem that students do not reach the minimum standard criteria score specified 70. Classroom action research used in this study uses the Jigsaw Cooperative Learning Model. The results showed that there was an increase in teacher teaching skills and student achievement.

\section{Conclusion}

The Jigsaw method using an online model can be applied in various situations, especially conditions such as a country experiencing a pandemic because the student learning process must continue from home. With the online Jigsaw method, it is hoped that students will not experience boredom with more varied learning methods and cooperation between groups. With the development of technology, the Jigsaw method with the online model is not an obstacle because now is the era of digital learning 4.0. 
The online jigsaw method is more varied because it can use images and videos. With the online jigsaw method, students have more opportunities to express their opinions. prefer online jigsaw because it is not directly dealing with the teacher so it is not ashamed to express opinions. The jigsaw method makes students or group members responsible for the success of the group. With the online jigsaw method demands to be more creative and think fast. The online jigsaw method is very effective in a variety of conditions. The online jigsaw method improves students' ability to learn to process information and improve communication skills.

The jigsaw learning model with the online method can be applied to high school students and above if applied to junior high school students and below will experience a little difficulty. Suggestions that can be conveyed are, students must be equipped with technological knowledge and implementation techniques using software appropriately because there are still around students who still experience technological stuttering. This method can be applied by teachers or educators as an improvisation of the learning process, especially during the Covid -19 pandemic so that students do not experience boredom and as a strategy to improve student achievement in online learning.

\section{References}

[1] Aronson, E., \& Bridgeman, D. L. (1979). Jigsaw groups and the desegregated classroom: In pursuit of common goals. Personality and Social Psychology Bulletin, 5(4), 438-466.

[2] Aronson E., \& Patnoe S. (1997). The jigsaw classroom: building cooperation in the classroom (2nd ed). Wokingham: Addison- Wesley Educational Publishers Inc

[3] Aronson, E. (2005). The jigsaw classroom. Retrieved March, 27, 2014, from http://www.jigsaw.org

[4] Azmin, N. H. (2015). Effect of the JigsawBased Cooperative Learning Method on Student Performance in the General Certificate of Education Advanced-Level
Psychology: An Exploratory Brunei Case Study. International Education Studies, 9(1), 91. https://doi.org/10.5539/ies.v9n1p91

[5] Cooper, J. L., Robinson, P., \& McKinney, M.(1994). Cooperative learning in the classroom. In D. F. Halpern \& Associates (Eds.), Changing college classrooms (pp. 74-92). San Francisco: Jossey-Bass.

[6] Evans, B. (2007). Student Attitudes, Conceptions, and Achievement in Introductory Undergraduate College Statistics. Mathematics Educator, 17(2), 24-30.

[7] Fitzmaurice, O., Leavy, A., \& Hannigan, A. (2013). Why is statistics perceived as difficult and can practice during training change perceptions? Insights from a prospective mathematics teacher. Teaching Mathematics and Its Applications, 33(4), 230-248.

https://doi.org/10.1093/teamat/hru010

[8] Gloria Ibemenji, K.-A., Sunday, E. I., \& Chijioke, O. P. (2019). Effect of Cooperative Learning Strategy on Biology Students' Academic Performance in Senior Secondary School in Rivers State. Journal of Scientific Research and Reports, 23(6), 1-11. https://doi.org/10.9734/jsrr/2019/v23i6301 38

[9] Goss-Sampson, M. A. (2018). Statistical Analisis In JASP: A Guide For Students. Retrieved from http://library1.nida.ac.th/termpaper6/sd/25 54/19755.pdf

[10] Hakim, L., \& Canda Sakti, N. (2019). Implementation of Jigsaw Type Cooperative Learning Model to Improve Economics Learning Results. International Journal of Educational Research Review, 350-357. https://doi.org/10.24331/ijere.573871

[11] Hedeen, T. (2003). The Reverse Jigsaw: A process of cooperative learning and discussion. Teach. Social, 31(3), 325-332. 
[12] Johnson, D. W., \& Johnson, R. (1994). Leading the cooperative school (2nd ed.). Edina, MN: Interaction Book Company

[13] Johnson, D. W., Johnson, R. T., \& Stanne, M. B. (2000). EXHIBIT B --Cooperative Learning Methods: A Meta Analysis Cooperative Learning Methods: A MetaAnalysis. 1-30.

[14] Kagan, S. (1994). Cooperative Learning. San Clemente, California: Kagan Publishing.

[15] Karacop, A. (2017). The Effects of Using Jigsaw Method Based on Cooperative Learning Model in the Undergraduate Science Laboratory Practices. Universal Journal of Educational Research, 5(3), 420-434.

https://doi.org/10.13189/ujer.2017.050314

[16] Khine, S. M., Nyunt, T. T. S., Maw, A. A., \& Min, S. S. (2019). Effective Learning for Higher Education Using Jigsaw Approach. (May), 1-5.

[17] Kordaki, M. (2014). the Jigsaw Collaborative Method Within the. (October).

[18] Miaz, Y. (2015). Improving Students' Achievement of Social Science By Using Jigsaw Cooperative Learning Model at Primary School. IOSR Journal of Research \& Method in Education Ver. II, 5(4), 2320-7388. https://doi.org/10.9790/738805420107

[19] Nurvita, Sinaga, B., \& Mukhtar. (2020). Analysis of Metacognition Difficulties and Mathematical Connections of Students using the Jigsaw Type Cooperative Learning Model. 384(Aisteel), 24-28. https://doi.org/10.2991/aisteel-19.2019.6

[20] Purba, P. B., \& Sinaga, B. (2020). The Effect of Problem Based Learning Model and Cooperative Learning Model Jigsaw type on Creative Thinking Skills Based on Students Learning Motivation. 384(Aisteel), 334-339. https://doi.org/10.2991/aisteel-19.2019.72

[21] Şahin, A. (2011). Effects of Jigsaw III technique on achievement in written expression. Asia Pacific Education Review, 12(3), 427-435. https://doi.org/10.1007/s12564-010-91358

[22] Slavin, R. E. (1991) Synthesis of research on cooperative learning. Educational Leadership, 48(5), 71-82.

[23] Slavin, R. 1995. Cooperative Learning: Theory, research, and Practise. Boston : Allyand and Bacon Publishers

[24] Strother, D. B. (1990). Cooperative learning: Fad or foundation for learning. Phi Delta Kappan, 72, 158-162.

[25] Walker, I., \& Crogan, M. (1998). Academic performance, prejudice, and the jigsaw classroom: new pieces to the puzzle. Journal of Community \& Applied Social Psychology, 8(6), 381-393. https://doi.org/10.1002/(sici)10991298(199811/12)8:6<381::aidcasp457>3.3.co;2-y

[26] Weidman, R., \& Bishop, M. J. (2009). Using the Jigsaw Model To Facilitate Cooperative Learning in an Online Course. Quarterly Review of Distance Education, 10(1), 51-64,89,91.Retrievedfrom http://search.proquest.com/docview/23106 8932 ? accountid $=14645$ 